\title{
The Value and Application Path of Displaying Virtual Architecture and Cultural Heritage
}

\author{
Aifeng Wang', Bei Wang ${ }^{2}$ \\ ${ }^{1}$ Nanyang Institute of Technology, Nanyang City, Henan Province, 473004, China \\ ${ }^{2}$ Zhengzhou Foreign Language School, Zhengzhou City, Henan Province, 450000, China
}

Keywords: Virtual architecture; Cultural heritage; Value; Application path

\begin{abstract}
The construction of cultural heritage virtual reality refers to the use of digital technology, mainly virtual reality technology, making rehabilitation, simulation, reproduction, displaying and preservation on the ancient architecture, ruins and cultural relics through the computer. It is a perfect combination of science, technology and art. Based on the author's learning and practical experience, this paper first analyzed the value of virtual architecture and cultural heritage displaying, and then discussed the application path of the virtual architecture and cultural heritage.
\end{abstract}

\section{Introduction}

The development of modern science and technology has expanded the field of the cultural heritage of virtual architecture displaying. People do not need to visit and study directly to the architectural cultural sites. To create a realistic 3D simulation scene and see the original appearance of the architectural cultural heritage is only through high-performance graphic workstations. We then projector it on a large screen with the sound, resulting in immersive audio-visual effects.

\section{The Value of Displaying Virtual Architecture and Cultural Heritage}

At present, the heritage of historical and geographical browsing roaming based on virtual reality technology in the concept of virtual heritage for its research, protection, the humanities history and natural geography can play a very important role. This has been widely recognized internationally. Therefore, the virtual reality technology used to reconstruct the cultural heritage buildings and establishing a three-dimensional virtual interactive system are not only preserves the original data of the cultural relics, but also can reconstruct the damaged buildings. It can also restore the original style of architectural heritage and provide a scientific and intuitive basis for the protection and development of architectural heritage. On the premise of the protection and protection principle mentioned above, the research on digital protection of architectural heritage using virtual simulation technology is mainly in the following aspects:

First, it will help to improve the displaying effect of cultural relics buildings. When the virtual reality system is applied to the protection of historical buildings, it can make the system simulate the original appearance of the historical buildings accurately and realistically. Observers can freely walk or even fly in the virtual environment of historical buildings, and go to any corner of the building and observe the building ruins in all directions. As a result, there are more people having a comprehensive and profound understanding of the architectural heritage.

The second is helps to improve the protection of cultural relics building technology. There are a lot of fragile constructions in the cultural relic buildings, and all of them are prone to embrittlement, decoloration and spalling. Even after artificial restoration, they are still difficult to be used for research and display. Using the virtual reality technology, we can show the image of the restoration of the historical relic building in advance, so as to test the feasibility of the restoration technology, and further combine it with the view computing technology. Inspect the links in the process of restoration and the virtual technology after restoration with displaying the cultural relics from many angles in a large amount and well, make the cultural relics can be stored in a more rigorous 
environment. This is beneficial to the extension of the life of the cultural relic building in the virtual reality system. After processing and processing the data in advance, the observer can add and modify objects in the virtual environment of the historical building in real time. This makes it possible for the designers and decision-makers to evaluate the results of construction and reconstruction of historical and environmental buildings in different ways. Moreover, it adds experience and contrast to different plans of the project, so as to strengthens the scientificalness and accuracy of decision-making.

Third is to help break through the limitations of time and space, and give full play to the value of the architectural heritage. China has a large number of cultural relics construction. Because of the traffic jam, the value of the cultural relic buildings can not be brought into play. The virtual reality technology provides the technical means of non visual perception of the original cultural relics. It can be used to demonstrate the remains of the excavated or destroyed sites according to archaeological research data and literature records. It can also integrate the cultural relics resources through the network technology and spread it to the whole society, but it will not affect the security of the building heritage itself.

Fourth is conducive to the integration and sharing of architectural heritage and related cultural relics and historical resources. A virtual building environment can contain rich, complete data and data related to objects. We can build a database of relevant information for a particular historical building. The data of the database are all digitized data and data, and the contents of the database can be related to the three-dimensional model of the virtual environment. The observer investigation and experience in 3D virtual environments can be real-time access to relevant data and access to the object of interest and information. We can integrate the large cultural heritage resources through computer networks. In addition, we can also use the network and virtual technology in a wide range, displaying cultural relics buildings in a more comprehensive, vivid and realistic way. Consequently, cultural relics are separated from geographical restrictions and realize the sharing of resources, and truly become a cultural heritage that all mankind can possess.

\section{The Application Path of the Virtual Architecture and Cultural Heritage}

Formulate concrete rehabilitation design scheme. The application of virtual reality technology to the restoration of ancient buildings needs to be planned before the application of the project, so as to ensure the scientific and rational design: first of all, we have to decide what kind of virtual reality expression we choose; next, according to the project, we should make sure to choose photo browsing or 3D experience. Secondly, we should consider where the final display platform of the virtual ancient architecture system is, and assure whether it is in the virtual laboratory or the digital museum. We have to make reasonable arrangements for the time according to the actual situation of the project to plan the production time. According to the specific restoration design requirements, we have to select the corresponding virtual works of size, resolution, and the clarity of the work and other parameters.

Interim production process. This part mainly uses the virtual reality technology to make the ancient architecture system. The process mainly includes: first, the field inspects the ancient architecture. Through the field inspection of ancient buildings, we measure the specific data to obtain the basic situation of ancient buildings. The measurement focuses on the data of the ancient building plane, the data of the facade, and even the data of the section. If the conditions permit, you should also measure the surrounding environmental data; second is to take photos. We also take photos of the ancient buildings while measuring the data. First of all, we should pay attention to the integrity of the picture. Secondly, we should ensure that the material of the picture is taken, and the object is not overexposed; the third is to sort out the relevant information. We collect and analyze the data of on-the-spot investigation; fourth is the establishment of three-dimensional model. In order to ensure the smooth operation of the final virtual architecture, we need to optimize the model design. We need to think about making the model and try to make the best scene with the least amount and the texture. In the aspect of model making and in order to achieve the rendering effect, we try to represent the model with the least amount of face; fifth is the scene mapping, lighting and 
baking processing. Since ancient buildings are older, direct photographs can not be used directly to make maps. Thus, we need to fix the map, and fix the photos, colors, textures, brightness, contrast and so on. The purpose is to make the texture more realistic and complete, so as to better serve the model map; sixth is virtual roaming and interactive synthesis. In the process of virtual roaming and interactive synthesis, we should pay special attention to the logic of programs or interactive modules.

The post production of the virtual ancient buildings reconstruction. The goal of this stage is to test the virtual reality system, so that to verify the compatibility, versatility and stability of the system. The specific test method is: test under different operating system platform and on different hardware configuration machines and operate tests by different users.

The unity of representation and expression. Reproduction and expression are two basic means and methods of writing. Reproduction focuses on the objective features of the object, and reflects the author's subjective feelings. In the creative technique, emphasis is placed on realism and verisimilitude, that is, the perfection of perceptual form and the reality of phenomena; in the creative tendency, we emphasize the understanding of the object and the reappearance of the reality. Its characteristic is perceptual reality and sober reason playing a leading role accompanied by careful observation and strict techniques. But the reappearance of art is not a mechanical reflection of reality, and it is not a purely objective reality. It is the artist in accordance with the laws of beauty, and it knows the reality of the use of lines, colors, materials and other materials embodied in the media. This is inseparable from the artist's understanding, selection, refinement, processing and transformation. But for a long time, virtual architecture and cultural heritage have been studied as an engineering technique. People are accustomed to using high-tech to describe from the surface of architecture, and satisfied with the research of program technology and various algorithms. They only noticed the work involved in computer hardware, programming, running environment, and so forth. They seldom pay attention to the culture and aesthetics of architectural heritage from form to content, from partial to whole, from phenomenon to essence. Therefore, people ignore the fact that the virtual architecture heritage belongs to an art, and it has the beauty and cultural connotation. The unity of representation and representation is actually the unity of "technical" and "artistic" in the cultural heritage of virtual architecture. Namely, in the virtual reality of the building, it emphasizes the art of space, shape, material and light and shadow, enhances the atmosphere of space rendering, showing the architectural heritage more realistically and increasing the visibility of the work. For example, the author is in process of "the design and manufacture of Shanghai ordinary virtual reality demonstration system". Through the implementation process of the two site and the surrounding environment of digital virtual reproduction, the author fully aware that the virtual reality technology is to build auxiliary means in the process of building virtual cultural heritage. Artistic performance plays an equally important role in this process--creating the architectural space and local components, processing materials and space lighting effects, halo, atmosphere, fog and atmosphere, should belong to the two basic problems of modeling and color in the process of art and design. Its authenticity belongs to perceptual truth or artistic truth, and should be solved through artistic expression.

\section{Summary}

The application of virtual reality technology to the restoration of ancient architecture has important practical significance for improving the protection of ancient architectural heritage and improving the scientific nature of rehabilitation design. Virtual reality technology can give a good protection effect to the whole environment restoration scheme of ancient architecture. Therefore, in the future reconstruction of ancient architecture, the use of virtual reality technology is an important measure for the protection of ancient architecture. 


\section{Acknowledgements}

Fund project: Key scientific and technological project of Henan Province in 2015: A study on spatial optimization strategy of immigrant new village - Taking Nanyang city as an example. (152102310026)

\section{References}

[1] Wang Wei. Research on Design and Implementation of Interactive Interaction of Virtual Ancient Architecture[D]. Shanxi University, 2014.

[2] Zhang Li. Study on the Application of Virtual Reality Technology in Architectural Heritage Conservation[D]. Jiangnan University, 2009.

[3] Dong Yue, Liu Xiaodong. Research on the Artistic Nature of the Cultural Heritage of Virtual Architecture.[J]. Review of Films, 2009, (06): 85+105.

[4] Dong Yue. On the Representation of the Cultural Heritage of the Virtual Architecture[J]. Popular Literature and Art (Theory), 2009, (01): 133-134.

[5] Dong Yue. The Artistic Nature and Authenticity of the Cultural Heritage of the Virtual Architecture[J]. Mass Literature and Art (Theory), 2008, (12): 139-140.

[6] Shi Kunpeng. Analysis on the Characteristics and Necessity of the Study of the Exhibition of the Cultural Heritage of Virtual Architecture[J]. Art and Design Research (Theory), 2008 (08): 35-36.

[7] Dong Yue. Technical and Artistic Research on the Cultural Heritage of Virtual Architecture[D]. Donghua University, 2006. 